\title{
Control of flowering time and spike development in cereals: the earliness per se Eps-1 region in wheat, rice, and Brachypodium
}

\author{
Maria E. Faricelli • Miroslav Valárik • Jorge Dubcovsky
}

Received: 10 August 2009/Revised: 22 September 2009 / Accepted: 26 September 2009/Published online: 23 October 2009

(C) The Author(s) 2009. This article is published with open access at Springerlink.com

\begin{abstract}
The earliness per se gene Eps- $A^{m} 1$ from diploid wheat Triticum monococcum affects heading time, spike development, and spikelet number. In this study, the Eps 1 orthologous regions from rice, Aegilops tauschii, and Brachypodium distachyon were compared as part of current efforts to clone this gene. A single Brachypodium BAC clone spanned the Eps-A $A^{m} 1$ region, but a gap was detected in the A. tauschii physical map. Sequencing of the Brachypodium and A. tauschii BAC clones revealed three genes shared by the three species, which showed higher identity between wheat and Brachypodium than between them and rice. However, most of the structural changes were detected in the wheat lineage. These included an inversion encompassing the wg241-VatpC region and the presence of six unique genes. In contrast, only one unique gene (and one pseudogene) was found in Brachypodium and none in rice. Three genes were present in both
\end{abstract}

\begin{abstract}
Sequences deposited in this study EU358770 (BAC clone RI101M3), EU358773 (BAC clone HI6P23), EU358772 (BAC clone DH027O19), GQ422598 (Mot1 T. monococcum DV92), EU358774 (Mot1 T. monococcum G3116), GQ422597 (FtsH4 T. monococcum DV92), EU379332 (FtsH4 T. monococcum G3116).
\end{abstract}

Electronic supplementary material The online version of this article (doi:10.1007/s10142-009-0146-7) contains supplementary material, which is available to authorized users.

\footnotetext{
M. E. Faricelli $\cdot$ M. Valárik · J. Dubcovsky $(\square)$

Department of Plant Sciences, University of California,

Mail Stop 1, One Shields Avenue,

Davis, CA 95616-8780, USA

e-mail: jdubcovsky@ucdavis.edu

Present Address:

M. Valárik

Laboratory of Molecular Cytogenetics and Cytometry, Institute of Experimental Botany,

Olomouc, Czech Republic
}

Brachypodium and wheat but were absent in rice. Two of these genes, Mot 1 and Fts H4, were completely linked to the earliness per se phenotype in the T. monococcum highdensity genetic map and are candidates for $E p s-A^{m} 1$. Both genes were expressed in apices and developing spikes, as expected for $E p s-A^{m} l$ candidates. The predicted MOT1 protein showed amino acid differences between the parental T. monococcum lines, but its effect is difficult to predict. Future steps to clone the Eps-A $A^{m} l$ gene include the generation of mot 1 and ftsh 4 mutants and the completion of the T. monococcum physical map to test for the presence of additional candidate genes.

Keywords Comparative genomics - Earliness per se. Flowering $\cdot$ Wheat $\cdot$ Brachypodium

\section{Introduction}

Positional cloning of genes in wheat is hampered by its large genome size with abundant repetitive elements and its polyploid nature. Common wheat Triticum aestivum L. has a 16.4-Gb genome (Arumuganathan and Earle 1991) with a large proportion of repetitive elements (approximately $80 \%$, Moore 1995) and three different genomes $(2 n=6 x=42$, AABBDD genomes). These three genomes originated from the hybridization of diploid Aegilops tauschii Coss. $(2 \mathrm{n}=2 \mathrm{x}=14, \mathrm{DD}$ genome $)$ and tetraploid Triticum turgidum $\mathrm{L}$. $(2 \mathrm{n}=4 \mathrm{x}=28$, AABB genomes $)$. The AA genome from tetraploid wheat was contributed by Triticum urartu Tumanian ex Gandilyan $(2 \mathrm{n}=2 \mathrm{x}=14$, AA genome), which is closely related to cultivated diploid wheat Triticum monococcum L. $\left(2 \mathrm{n}=2 \mathrm{x}=14, \mathrm{~A}^{\mathrm{m}} \mathrm{A}^{\mathrm{m}}\right.$ genome, Dvorak et al. 1993; Johnson and Dhaliwal 1976). The BB genome was contributed by a species from the 
Sitopsis group, likely related to Aegilops speltoides (Tausch) Löve (Dvorak and Zhang 1990; Huang et al. 2002; Liu et al. 2003).

The use of wheat diploid ancestors (or other diploid Triticeae species) provides a viable alternative to overcome the complications imposed by polyploidy to positional cloning projects. The development of molecular markers and the construction of high-density genetic maps are considerably simpler in diploid genomes. Examples of the use of this strategy are provided by the cloning of the powdery mildew resistance locus $P m 3$ of hexaploid wheat using both tetraploid and diploid wheat (Yahiaoui et al. 2004), and by the use of T. monococcum to clone the vernalization genes Vrn1 and Vrn2 (Yan et al. 2003, 2004) and the leaf rust resistance locus $\operatorname{Lr} 10$ (Stein et al. 2000).

The large size of the Triticeae genomes has delayed the sequencing of these species and limited the number of successful positional cloning projects in this economically important group of plants. Fortunately, there is good colinearity among species of the Poaceae family (Devos 2005; Devos and Gale 2000; Feuillet and Keller 2002; Paterson et al. 2000; Van Deynze et al. 1995). The available genomic sequences of rice (Goff et al. 2002; Yu et al. 2002) and Brachypodium (http://www.brachypodium.org) provide parallel road maps, which are useful to generate markers in the Triticeae-targeted regions, and in some cases, to identify potential candidate genes (Yan et al. 2003, 2006). This comparative genomics approach has been used in most of the positional cloning projects in wheat (Bossolini et al. 2006; Feuillet et al. 2003; Fu et al. 2009; Uauy et al. 2006; Yan et al. 2003, 2004, 2006).

Whereas the initial low-resolution restriction fragment length polymorphism (RFLP) maps were sufficient to reveal the existence of large colinear chromosome blocks between rice and wheat, they were unable to detect small rearrangements affecting this colinear frame (Devos 2005; Dubcovsky et al. 1996; Guyot and Keller 2004; Linkiewicz et al. 2004; Peng et al. 2004; Sorrells et al. 2003). The development of high-density maps and the first comparative sequencing of targeted orthologous regions revealed numerous exceptions to the broad RFLP colinearity previously observed along large blocks of rice and wheat chromosomes. These alterations were generated by gene duplications, deletions, and inversions as well as gene insertions associated with transposition of linked retroelements (Bennetzen and $\mathrm{Ma}$ 2003; Bennetzen and Ramakrishna 2002; Brunner et al. 2003; Dubcovsky et al. 2001; Guyot et al. 2004).

The whole rice genomic sequence provided the framework for additional comparative studies with orthologous regions in the Triticeae genomes. These studies showed that the intergenic regions in the large Triticeae genomes are mainly composed of repetitive elements that evolve rapidly and are not conserved with rice (Bennetzen and Ma 2003;
Dubcovsky et al. 2001; SanMiguel et al. 2002). A low conservation of the intergenic regions was also reported among different Triticeae genomes (Dubcovsky and Dvorak 2007; Gu et al. 2004; Kong et al. 2004; Wicker et al. 2003). In maize, some intergenic regions were shown to be highly variable even between inbred lines of the same species as a result of independent retrotransposon invasions in different maize progenitor plants ( $\mathrm{Fu}$ et al. 2002; Song and Messing 2003).

An additional source of exceptions to the broad gene colinearity observed between rice and the Triticeae genomes is the existence of an ancestral polyploidization event that predated the divergence of the rice and wheat lineages (Paterson et al. 2004). Deletions in the duplicated regions occurred independently after the divergence of the two lineages, generating numerous alterations to the initial colinear regions. A well-studied example of this phenomenon is the chromosome region including the thermosensitive earliness per se gene Eps-A $A^{m} l$ located on the distal region of T. monococcum chromosome $1 \mathrm{~A}^{\mathrm{m}} \mathrm{L}$. Searches of the most similar rice genes using wheat genes from this region returned orthologues from both rice chromosomes 1 and 5, which originally belong to a single region duplicated in the ancestral polyploidization event (Valárik et al. 2006).

The current interest in the cloning of the Eps- $A^{m} l$ gene has recently increased with the discovery that, in addition to its effect on heading time, this gene affects the number of spikelets and grains per spike in diploid wheat (Lewis et al. 2008). The effect on heading time was explained by differences in the timing of the transition between the vegetative and reproductive stages and the duration of spike development (no significant effects were found in the stem elongation period; Lewis et al. 2008). The $E p s-A^{m} 1$ gene was initially mapped distal to marker wg241 on the telomeric region of diploid wheat chromosome $1 \mathrm{~A}^{\mathrm{m}} \mathrm{L}$ (Bullrich et al. 2002) and later mapped more precisely to a 0.8-cM interval between genes VatpC and Adkl (Valárik et al. 2006). Colinearity between the ends of both rice chromosome 5 and wheat chromosome $1 \mathrm{~A}^{\mathrm{m}} \mathrm{L}$ was interrupted by a small inversion, several non-colinear genes, and a non-colinear region between markers $\operatorname{Vatp} C$ and $A d k 1$ (Valárik et al. 2006). Even after using all the available genes from the rice colinear region, the interval between the markers flanking the Eps- $A^{m} l$ locus was not small enough to start a chromosome walk to ultimately clone the gene.

In this study, the physical map of A. tauschii (http:// wheat.pw.usda.gov/PhysicalMapping/) and the diploid Brachypodium distachyon (L.) Beauv sequence were utilized to generate additional markers in the Eps- $A^{m} 1$ region and identify potential candidate genes. Brachypodium has recently emerged as an alternative model species for Triticeae because of its closer phylogenetic distance to these species than rice (Draper et al. 2001). The estimated 355-Mb 
genome of Brachypodium places it in an intermediate position between Arabidopsis and rice in terms of genome size (Bennett et al. 2000). Additional genomic resources for this species are already available, such as 20,449 expressed sequence tags (ESTs) from five $B$. distachyon cDNA libraries (Vogel et al. 2006).

\section{Materials and methods}

Mapping populations

Mapping populations used in the construction of the T. monococcum high-density genetic map are all derived from the cross between cultivated T. monococcum ssp. monococcum accession DV92 (spring growth habit) carrying the Eps-A $A^{m} l$ allele for late heading, and wild T. monococcum ssp. aegilopoides accession G3116 (winter growth habit) carrying the Eps- $A^{m} 1$ allele for early heading. These mapping populations included $74 \mathrm{~F}_{2}$ lines, $343 \mathrm{~F}_{3: 2}$ additional families, $96 \mathrm{~F}_{5}$ single-seed descent (SSD) lines, and 3,298 $\mathrm{BC}_{5} \mathrm{~F}_{2}$ near isogenic lines (NILs), all of them described before (Lewis et al. 2008; Valárik et al. 2006). Plants were screened with polymerase chain reaction (PCR) markers flanking the Eps- $A^{m} 1$ region (Table 1), and only those with recombination events within the targeted region were retained. Progeny tests for heading time were performed for plants carrying critical recombination events within the Eps- $A^{m} 1$ region (Lewis et al. 2008; Valárik et al. 2006).

BAC selection, sequencing, and annotation

BAC libraries from A. tauschii accession AS75 (181,248 clones, 4.1-fold coverage, Akhunov et al. 2005), B. distachyon accession Bd21 (36,864 clones, 11.6-fold coverage, Huo et al. 2006), and T. monococcum ssp. monococcum accession DV92 (276,000 clones, 5.6-fold coverage, Lijavetzky et al. 1999) were screened by hybridization and/or PCR with probes derived from markers in the Eps- $A^{m} 1$ region (Table 1). Positive BAC clones were HindIII-fingerprinted, and contigs were manually assembled. BAC-end sequencing was performed using primers from the T7 and SP6 ends of the BAC vector to confirm contig assembly. Selected BAC clones from $A$. tauschii and $B$. distachyon were sequenced and annotated using a combination of tools, including comparative genomics analyses, BLAST searches, and gene-finding programs (Dubcovsky et al. 2001). Sequences were assembled using the Phred/Phrap/Consed software (Ewing and Green 1998; Gordon et al. 1998). Gaps in the BAC sequences were filled by primer walking.

Sequence analysis

Sequences of the A. tauschii BAC clones RI101M3 and HI6P23, rice BAC clone AC130728, and B. distachyon BAC clone DH027O19 were compared using the on-line available Artemis Comparison Tool (Abbott et al. 2005). Additionally, exon and intron, and protein sequences of wheat, rice, and Brachypodium orthologous genes wg241, CA608558, and $\operatorname{VatpC}$ were compared using either BLASTN or BLASTP, accordingly.

Genomic DNA extraction, PCR, hybridization, and Southern Blot procedures were performed as described before (Dubcovsky et al. 1994).

Semi-quantitative and real-time quantitative PCR

RNA samples were obtained from four different $\mathrm{BC}_{5} \mathrm{~F}_{2}$ NILs derived from the DV92 $\times$ G3116 mapping population containing the closest recombination events flanking the Eps- $A^{m} 1$ locus (two at each side). NILs 268-5 and 268-3 have recombination events distal to Eps- $A^{m} 1$, and they carry Eps- $A^{m} 1$ alleles for early (G3116) and late (DV92) heading, respectively, whereas NILs 529-1 and 529-3 have recombination events proximal to Eps- $A^{m} 1$, and they both contain Eps- $A^{m} 1$ alleles for late heading (Lewis et al. 2008).
Table 1 Polymerase chain reaction markers developed in the Eps- $A^{m} 1$ region of Triticum monococcum

\begin{tabular}{|c|c|c|c|c|}
\hline Marker type & Locus & EST & Primers & Restriction enzyme \\
\hline CAP & $P 23 \_4$ & No & $\begin{array}{l}\text { GTTTGCTTTGGGGTGTTTGT } \\
\text { GGCTCCTAGCGAAGCTCAG }\end{array}$ & Cac8I \\
\hline CAP & Mot1 & CJ698500 & $\begin{array}{l}\text { AAGGACCTGTTTCAGTCCCATA } \\
\text { GTTGAGCTTCGCCAGGAACT }\end{array}$ & Bst $\mathrm{NI}$ \\
\hline CAP & FtsH4 & No & $\begin{array}{l}\text { CACATATCTGGCACCCACA } \\
\text { TGCTCATGAGTTTTCCTCTGAA }\end{array}$ & $T s p 509 \mathrm{I}$ \\
\hline RFLP & $C f 2.1$ & DV854615 & $\begin{array}{l}\text { TTTTGGGCTACTCGACAACC } \\
\text { TCTAAACAAGCAAGGGGACCT }\end{array}$ & $X b a \mathrm{I}$ \\
\hline CAP & Rbpl & BQ806744 & $\begin{array}{l}\text { CTTGTTGATGATTTCCATTGC } \\
\text { ATACATGAAAACTGCTGAAAGAGC }\end{array}$ & TseI \\
\hline LP & $A-C$ & No & $\begin{array}{l}\text { GGGCATATTTCCTTCACGGTA } \\
\text { CCGTGCCTCAGGTGTATCTT }\end{array}$ & \\
\hline
\end{tabular}

$C A P$ cleavage amplified polymorphism, RFLP restriction fragment length polymorphism; $L P$ length polymorphism 
Plants were grown in a growth chamber at a constant temperature $\left(16^{\circ} \mathrm{C}\right)$ and a long-day photoperiod $(16 \mathrm{~h}$ light, $\left.602 \mu \mathrm{E} \mathrm{m}^{-2} \mathrm{~s}^{-1}\right)$. Shoot apical regions were dissected using magnifying glasses, and multiple apices from the same genotype and at the same developmental stage were pooled for RNA extraction. Apices were collected at the doubleridge stage and at the terminal spikelet stage. Total RNA was extracted using the RNeasy Plant Mini Kit (Qiagen, USA), and cDNA was then synthesized using the QuantiTect ${ }^{\circledR}$ Reverse Trancription Kit (Qiagen, USA).

Semi-quantitative and real-time quantitative PCR using SYBR $^{\circledR}$ Green JumpStart ${ }^{\mathrm{TM}}$ Taq ReadyMix ${ }^{\mathrm{TM}}$ (SigmaAldrich $^{\circledR}$, USA) were performed using primers $5^{\prime}$-TTTTT GCTCAACATAAGGCTTTC-3' and 5'-TCTGTCCATTGC CTGGAGAT-3' for T. monococcum gene Mot1, and primers 5'-CCCGCTGCTTAAGACATTGCAGA-3' and 5'-CCTCTTCATGCAATCCAAGGCCTTTAC-3' for T. monococcum gene FtsH4. Transcript levels of the eukaryotic initiation factor elf4a and Actin were used as endogenous controls in the semi-quantitative and real-time quantitative PCR, respectively. The elf4a endogenous control for the semi-quantitative PCR was amplified using primers forward 5'-TGCTGTTCGACATCCAGAAG-3' and reverse 5'-CCCAGACCTTACCACTCCAA-3', and Actin was amplified using primers forward 5'-ACCTTCAGTT GCCCAGCAAT-3' and reverse 5'-CAGAGTCGAGCACA ATACCAGTTG-3' (Uauy et al. 2006). The $2^{-\Delta \Delta C}{ }_{T}$ method (Livak and Schmittgen 2001) corrected for primer amplification efficiency was used to normalize and calibrate the Motl and Fts $H 4 C_{T}$ values relative to the Actin endogenous controls.

The real-time quantitative PCR data was analyzed as a $2 \times 2$ factorial analysis of variance (ANOVA) with genotype (Eps- $A^{m} 1$-early (G3116) and Eps- $A^{m} 1$-late (DV92) alleles, four different recombinant lines) and developmental stage (double-ridge and terminal spikelet) as factors. Replications including all four treatments were performed in two different growth chambers under the same conditions described above, which were included in the analysis as blocks (Randomized Complete Block Design).

\section{Results}

A. tauschii genes and physical map

A chromosome walk was initiated in A. tauschii to take advantage of the available physical map (http://wheatdb. ucdavis.edu:8080/wheatdb/index.jsp). The A. tauschii BAC library was screened with probes derived from both proximal and distal markers flanking the Eps- $A^{m} 1$ locus, and the new genes identified in each region are described below.
Eps- $A^{m} 1$ proximal side The screening of the A. tauschii BAC library with a probe derived from the proximal singlecopy gene $w g 241$ (54\% identical to rice hypothetical protein EEC79795.1) yielded four positive BAC clones (RI1C16, HI92F1, BB19D17, and RI101M3). These clones are part of the A. tauschii contig 2863 (D genome assembly 1.1), which includes $133 \mathrm{BAC}$ clones, and covers approximately $2.3 \mathrm{Mb}$. All four BAC clones selected with $w g 241$ contained gene CA608558, but only BB019D17 and RI101M3 included also the VatpC gene. The BAC clone RI101M3 (approximately $125 \mathrm{~kb}$ ) was sequenced, annotated, and deposited in GenBank (EU358770). In addition to the three genes previously detected in rice and mapped in $T$. monococcum (wg241, CA608558, and VatpC, Valárik et al. 2006), six new genes were identified in this BAC clone (Fig. 1d).

Starting from the proximal end of the BAC clone RI101M3, the first two genes are the previously mapped $w g 241$ and CA608558 (Valárik et al. 2006), followed by CD892187__ and CD892187_2, which are not present in the rice colinear region. The predicted proteins encoded by these two genes (ACT34065.1 and ACT34066.1, respectively) are 61\% identical $(70 \%$ similar) to each other. The temporary name of this locus (CD892187) is based on the $98 \%$ identity of the predicted coding region of gene CD892187_1 to T. aestivum EST CD892187 (85\% identity with gene CD892187_2). The two predicted proteins are $41 \%$ (ACT34065.1) and $44 \%$ (ACT34066.1) identical to rice hypothetical protein EEE62901. The function of this protein is currently unknown.

The duplicated CD892187 genes are followed by a gene designated $\mathrm{Poz}$, which encodes a protein $58 \%$ identical to rice protein $\mathrm{BAD} 16239.1$ (located in a non-colinear rice chromosome region, Fig. 1a). This protein is a member of the speckle-type POZ protein family and contains an Nterminal MATH domain (cd00121) and a C-terminal POZ domain (pfam00651). POZ domains from several zinc finger proteins have been shown to mediate transcriptional repression and to interact with components of histone deacetylase co-repressor complexes.

Distal to the $\mathrm{Poz}$ gene, an additional non-colinear gene was detected based on its $86 \%$ identity to barley EST BG301142.1. This gene, designated Ap2-like (Ap2-L), encodes a protein that includes a single AP2 DNAbinding domain (cd00018), a domain found in many transcriptional regulators in plants (e.g., APETALA2 and EREBP). APETALA2-like proteins that play a role in plant development usually contain two copies of this domain instead of the single one observed in this protein.

The most distal genes present in the BAC clone RI101M3 (distal to the VatpC gene) are also absent in the rice colinear region. These genes, designated $C f 2.1$ and $C f 2.2$, encode proteins that are $55 \%$ and $54 \%$ identical to sorghum 


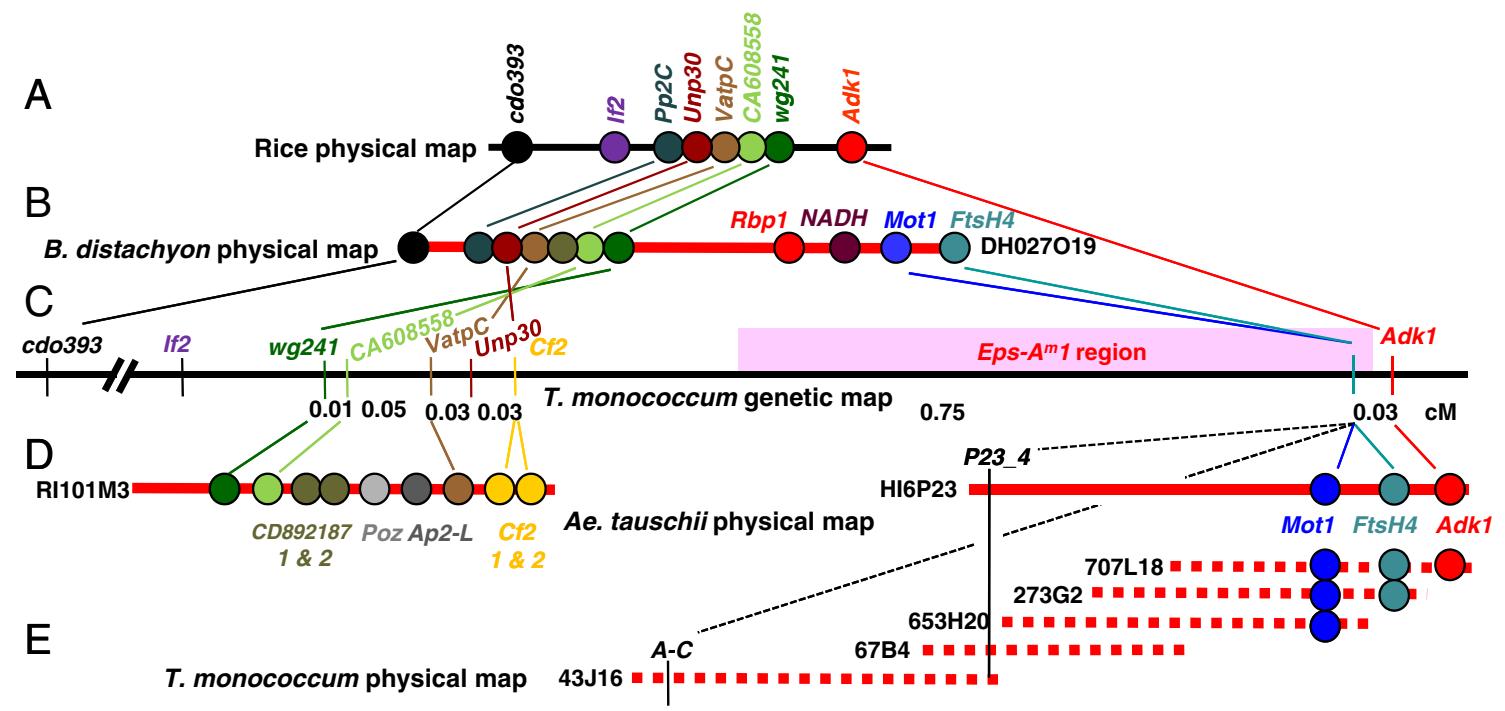

Fig. 1 a Schematic representation of the rice genomic sequence. b Brachypodium distachyon physical map, BAC clone DH027O19 covering the complete Eps- $A^{m} 1$ region. c Triticum monococcum high-density genetic map. d Aegilops tauschii physical map. e $T$.

Cf2/Cf5-like disease resistance protein ACE86403.1 from the LRR_RI (leucine-rich repeat, ribonuclease inhibitor)-like subfamily (c102423), respectively.

Eps- $A^{m} 1$ distal side The hybridization of the $A$. tauschii BAC library with a probe developed from the single-copy gene $A d k 1$ (91\% identical to rice putative protein kinase ADK1, AAT44307.1) yielded BAC clones RI3H10, HD66L22, and HI6P23. The clone RI3H10 is part of the A. tauschii contig 9849 (D genome assembly 1.1), which includes nine BAC clones and covers a region of approximately $245 \mathrm{~kb}$. The other two BAC clones were assigned to the same contig by HindIII-fingerprinting. Among these three BAC clones, HI6P23 (approximately $145 \mathrm{~kb}$ ) was the one that extended further into the proximal region, and it was selected for sequencing.

The sequence of the BAC clone HI6P23, which was annotated and deposited in GenBank (EU358773), revealed two genes that were not colinear with rice in addition to the colinear Adkl gene (Fig. 1a, d). The first one (from the proximal to the distal end of the BAC clone) was designated Mot1 based on a phylogenetic analysis of the conserved domains of the predicted protein (Fig. S1a, supplemental online material). Mot1 encodes a protein $84 \%$ identical to rice SNF2 domain-containing protein BAD25208.1, and 36\% identical to Saccharomyces cerevisiae protein MOT1. This last protein is a TATA-binding protein-associated factor involved in transcriptional regulation. The second gene, designated FtsH4 according to a phylogenetic tree constructed from the conserved domains of the predicted protein (Fig. S1b), encodes a protein that is monococcum physical map. Genes are indicated as colored circles, other markers as lines, sequenced BAC clones as continuous red bars, and not sequenced ones as dashed lines. The telomere is located to the right of the genetic and physical maps

$80 \%$ and $81 \%$ identical to rice proteins NP_001043384.1 (FtsH4) and NP_001043385.1 (FtsH5). These two proteins are encoded by genes recently duplicated in rice, which are both homologous to Arabidopsis gene FstH4 (Fig. S1b).

In an attempt to extend the $A$. tauschii physical map from the distal side, the probe $P 23 \_4$ was designed from a non-repetitive sequence located $29 \mathrm{~kb}$ from the proximal end of the BAC clone HI6P23 (Table 1, Fig. 1d). The rescreening of the BAC library with this probe failed to identify any new $A$. tauschii BAC clone, which interrupted the chromosome walk from this direction in this library.

\section{B. distachyon genes and physical map}

As an alternative strategy to bridge the gap identified in the A. tauschii BAC library, a second chromosome walk was initiated in B. distachyon. The $B$. distachyon BAC library was first hybridized with a probe developed from the single-copy gene Mot1. A total of 17 positive BAC clones was detected, and the ends of six of them (DH022N11, DH025B20, DH026A02, DH027O19, DH035A19, and DH042C06) were sequenced. The T7-end of the clone DH027019 was 89\% identical to gene cdo393, and the SP6-end was $87 \%$ identical to gene FtsH4, at the DNA level, which suggested that this BAC clone was spanning the complete Eps1 orthologous region (Fig. 1b).

The BAC clone DH027O19 (approximately $118 \mathrm{~kb}$ ) was sequenced and deposited in GenBank (EU358772). The annotation of this clone revealed ten genes and one pseudogene $(N A D H)$. The predicted protein from the 
pseudogene $N A D H$ shows $98 \%$ identity with $B$. distachyon NADH dehydrogenase $27 \mathrm{kDa}$ subunit (ACF08644.1), but it includes a premature stop codon and a truncation of the last approximately 23 amino acids. The ten genes present in this BAC clone include nine previously found in either rice or A. tauschii (cdo393, Pp2C, Unp30, VatpC, CD892187, CA608558, wg241, Mot1, and FtsH4), and a non-colinear gene designated Rbpl (Fig. 1b). The protein sequence encoded by gene $R b p 1$ shows $74 \%$ identity with a rice putative RNA-binding protein (BAC79567) from the Mak16 multi-copy gene superfamily (pfam04874).

\section{T. monococcum high-density genetic and physical maps}

The new genes identified in the $A$. tauschii and $B$. distachyon sequences were used to generate molecular markers (Table 1), which were incorporated into the highdensity genetic map of the Eps- $A^{m} 1$ region in T. monococcum (Lewis et al. 2008; Valárik et al. 2006).

On the distal side, genes Mot1 and FtsH4 were mapped $0.03 \mathrm{cM}$ proximal to $A d k 1$ and completely linked to each other and to the Eps- $A^{m} l$ locus (Table 1, Fig. 1c). This result indicates that the $A$. tauschii BAC clone HI6P23 covers the distal side of the physical map of the Eps- $A^{m} 1$ region. Since Mot 1 and FtsH4 are completely linked to the earliness per se phenotype, they are both valid candidate genes for Eps- $A^{m} 1$.

On the proximal side, gene $C f 2.1$ was mapped $0.05 \mathrm{cM}$ distal to VatpC, but still $0.75 \mathrm{cM}$ proximal to the Eps-A $A^{m} 1$ locus (Table 1, Fig. 1c). This distance was too long to continue the chromosome walk from $C f 2.1$, and therefore, additional efforts to develop a marker closer to $E p s-A^{m} I$ were focused on the distal contig, specifically on the $A$. tauschii BAC clone HI6P23. Marker P23_4 (Table 1, Fig 1d), developed from the proximal end of the clone HI6P23, was incorporated into the high-density map, but unfortunately, it was still completely linked to genes Mot1 and FtsH4 and to the Eps- $A^{m} 1$ phenotype (Fig. 1c).

Since it was not possible to continue the chromosome walk from the A. tauschii distal BAC clone, an additional marker was developed from $B$. distachyon gene $R b p l$ (Table 1). This gene was located in the $B$. distachyon BAC clone DH027O19 between Mot1 and the genes mapped on the other side of the proximal gap of the Eps- $A^{m} 1$ region (Fig. 1b) and, therefore, was an interesting candidate to generate a marker within the proximal $0.75-\mathrm{cM}$ gap. Unfortunately, marker $R b p 1$ was mapped in a non-colinear region on $T$. monococcum chromosome $7 \mathrm{~A}^{\mathrm{m}}, 5 \mathrm{cM}$ from the RFLP marker wg420 (Dubcovsky et al. 1996).

The use of both $A$. tauschii and $B$. distachyon was a useful strategy to develop markers completely linked to the Eps- $A^{m} 1$ locus and complete the distal side of the T. monococcum physical map, but it was insufficient to identify a marker tightly linked to the Eps- $A^{m} l$ locus on the proximal side (Fig. 1). Therefore, a chromosome walk was initiated in T. monococcum from the closest markers to Eps $-A^{m} 1$ on the distal side. The screening of the BAC library with probes Mot 1 and P23_4 yielded positive BAC clones 707L18, 273G2, 653H20, 67B4, and 43J16. Using BAC-end sequencing, HindIII-fingerprinting, hybridization (for gene Mot1), and PCR markers (for both genes FtsH4 and $A d k 1$ ), these five BAC clones were organized into a single contig spanning approximately $400 \mathrm{~kb}$ (Fig. 1e).

An additional marker was then developed from the proximal SP6-end of the BAC clone 43J16. One of the primers for this marker included the junction between retrotransposons Angela (LTR, Gypsy) and Caspar (TIR, CACTA; Table 1, Fig. 1e), and was designated $A-C$. This marker failed to amplify a PCR product from the other four BAC clones from the T. monococcum contig, confirming its proximal position. Unfortunately, this marker was also completely linked to the Eps- $A^{m} 1$ locus in the T. monococcum high-density genetic map (Fig. 1c), indicating that additional chromosome walk steps are still necessary to complete the proximal side of the Eps- $A^{m} 1$ physical map in T. monococcum.

Comparison of the wheat, rice, and Brachypodium Eps- $A^{m} 1$ colinear regions

The regions between genes $c d o 393$ and $A d k 1$ in rice (approximately $58 \mathrm{~kb}$ ) and $c d o 393$ and FtsH4 in B. distachyon (approximately $117 \mathrm{~kb}$ ) resulted to be much smaller than the orthologous regions in either T. monococcum or A. tauschii (Fig. 1). Although the physical length of this region is unknown in the Triticeae species, it can be roughly estimated. The sequenced $A$. tauschii BAC clones RI101M3 and HI6P23 (approximately $265 \mathrm{~kb}$ ) plus the estimated length of the non-overlapping region of the $T$. monococcum BAC clone 43J16 (based on the HindIIIfingerprint) covered a region of approximately $350 \mathrm{~kb}$, which corresponds to a genetic distance of $0.14 \mathrm{cM}$ (Fig. 1c-e). Assuming a constant ratio between genetic and physical lengths across this region, the 2.2-cM region between genes cdo393 and Adk1 in T. monococcum can be estimated to be approximately $5,600 \mathrm{~kb}$.

The difference in the size of the Eps1 orthologous regions from wheat, rice, and Brachypodium was determined mainly by the expansion of some intergenic regions in the large Triticeae genomes due to the insertion of repetitive elements. In spite of this big size difference, the Eps 1 region revealed a relatively good level of conservation of gene content and order across species, altered by an inversion of the region flanked by genes $w g 241$ and VatpC in the wheat lineage, and by several gene insertions/ deletions (indels) and duplications (Figs. 1 and 2).

Both $A$. tauschii and $B$. distachyon shared three genes that were absent in the orthologous region on rice chromo- 


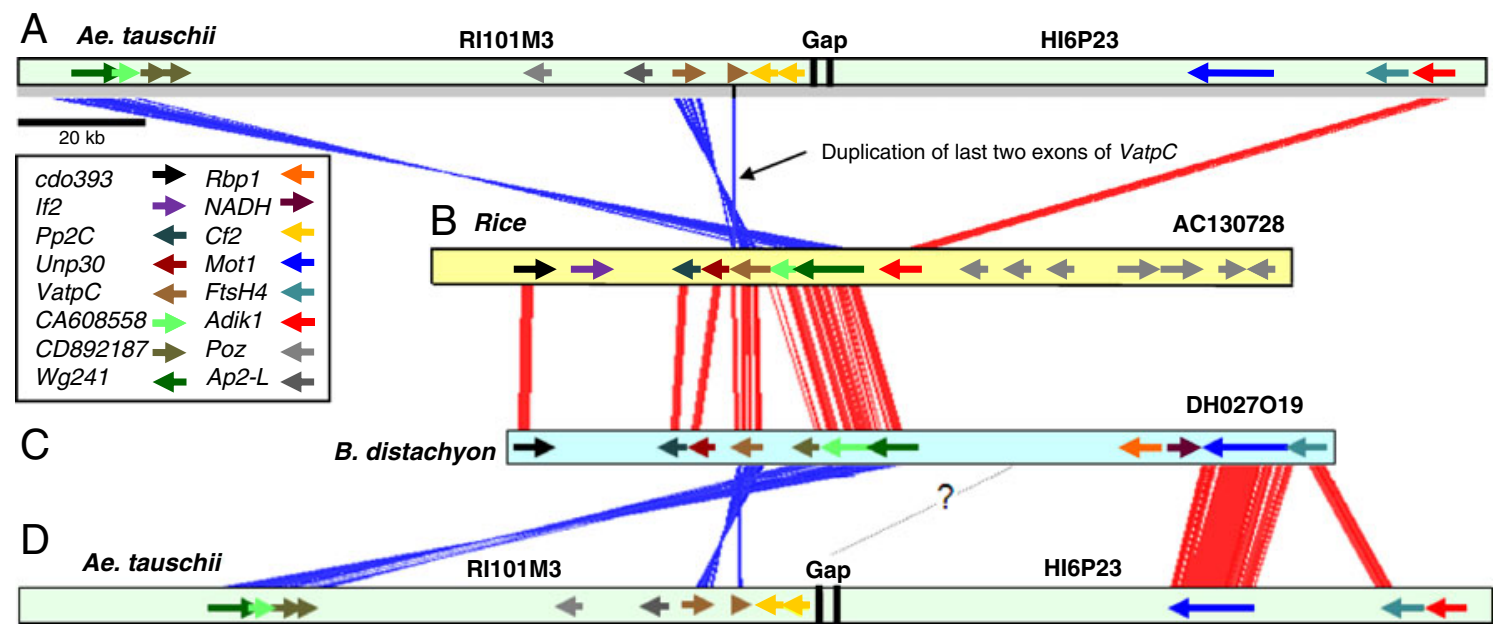

Fig. 2 Comparison of the sequences of Aegilops tauschii, rice, and Brachypodium distachyon Eps- $A^{m} 1$ colinear regions using the on-line Artemis Comparison Tool. Genes are indicated as colored arrows. a, d

some 5 (CD892187, Motl, and FtsH4, Figs. 1 and 2). The most similar rice gene to T. monococcum gene FtsH4 was found to be present on chromosome 1 between the paralogous copies of genes $P p 2 C$ and $A d k 1$, a region previously identified as the result of the ancestral polyploidization event that occurred before the divergence of the Poaceae genomes (Valárik et al. 2006). This suggested that the orthologous copy of T. monococcum gene FtsH4 on chromosome 5 was deleted in the rice lineage, but that the on wheat chromosome 1 and Brachypodium were not. The other two genes (CD892187 and Mot1) were absent in the rice orthologous or paralogous regions and may represent insertions in the wheat/Brachypodium lineage.

$B$. distachyon contained one unique gene $(R b p l)$ and a unique pseudogene $(N A D H)$, as well as a missing gene (If2), which was present in the other two species (Figs. 1 and 2). The Triticeae genomes showed four genes absent in both rice and B. distachyon (Poz, Ap2-L, Cf2.1, and Cf2.2), and a duplication of a gene present also in $B$. distachyon (CD892187). On the contrary, all the rice genes were present in either $B$. distachyon or the Triticeae genomes (Figs. 1 and 2). Genes $P p 2 C$ and Unp30 were identified in both rice and $B$. distachyon, but its presence in $A$. tauschii is currently unknown since they might be outside of the sequenced region (Figs. 1 and 2). Gene Unp30, however, was mapped in the $T$. monococcum high-density genetic map, $0.03 \mathrm{cM}$ between genes VatpC and $C f 2.1$ (Fig. 1c).

Sequence divergence among wheat, rice, and Brachypodium orthologous genes

Sequence identity across the wheat, rice, and Brachypodium genomes was restricted to gene regions (Fig. 2). Analyses of three orthologous genes present in the three
A. tauschii BAC clones RI101M3 and HI6P23. b Rice BAC clone AC130728. c B. distachyon BAC clone DH027O19

species (wg241, CA608558, and VatpC) revealed identical number of exons and conserved exon lengths across genomes. Intron size, however, was more variable across species. Thirty-four out of the 35 exon-intron boundaries found for the three orthologous genes in the three species contained the canonical GT and AG motifs, but the 15th intron of gene $\mathrm{wg} 241$ contained the alternative GC splicing site at the $5^{\prime}$ end in both wheat and rice, but not in Brachypodium.

Analyses of predicted proteins for these three orthologous genes revealed higher amino acid identity between wheat and Brachypodium than between these two species and rice (Fig. 3a-c). The combined exon regions for the three genes were more similar between wheat and Brachypodium ( $83 \%$ identity) than between wheat and rice $(75 \%$ identity) or Brachypodium and rice ( $80 \%$ identity) along the 6.5 to $7.0-\mathrm{kb}$ high-scoring segment pairs (HSP) aligned by BLASTN (Fig. 3d). These differences were even larger for the combined intron regions. Wheat and Brachypodium introns showed a significant BLASTN alignment along a 1,909-bp HSP (68\% identical), which was much smaller in the comparisons between wheat and rice (280-bp HSP, 67\% identical) or Brachypodium and rice (140-bp HSP, 74\% identical; Fig. 3e).

\section{Characterization of Eps- $A^{m} 1$ candidate genes}

Both candidate genes Motl and FtsH4 were sequenced from the two parental lines of the T. monococcum mapping population to test if the DV92 and G3116 Eps- $A^{m} 1$ alleles were associated with changes in the coding regions of these genes.

Alignment of the predicted MOT1 proteins showed two amino acid polymorphisms between the two parental lines: 


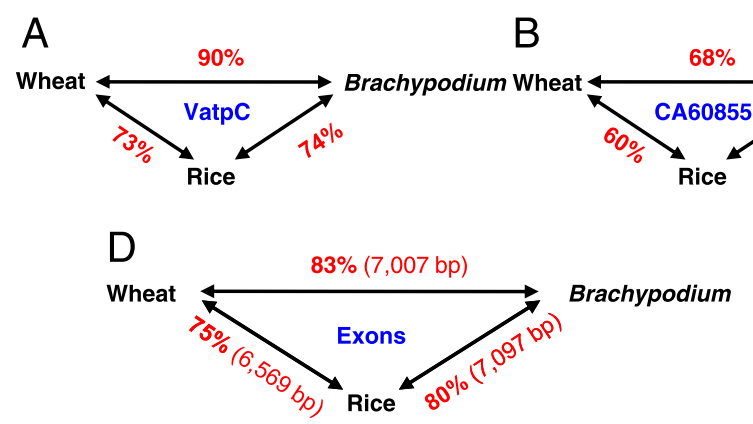

Fig. 3 Comparisons among the wheat, rice, and Brachypodium orthologous proteins and genes at the Eps- $A^{m} 1$ region. a-c Protein identity (\%). d Combined exon identity (\%) and length of the high-

isoleucine (I) vs threonine (T) at position 362 (BLOSUM62 score -2 ), and aspartic acid (D) vs glutamic acid (E) at position 460 (BLOSUM62 score 2). Alignment of wheat, rice, and Arabidopsis MOT1 proteins indicated that the amino acid changes occurred at non-conserved positions in the protein (Fig. S2).

Alignment of the predicted FtsH4 proteins from DV92 and G3116 showed no amino acid polymorphism.

To test if the phenotypic differences between the DV92 and G3116 Eps- $A^{m} l$ alleles were associated with changes in the expression of the candidate genes, transcript levels of
C

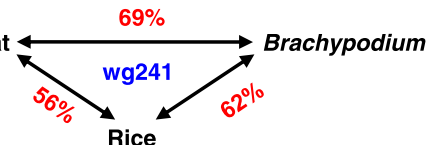

E Wheat

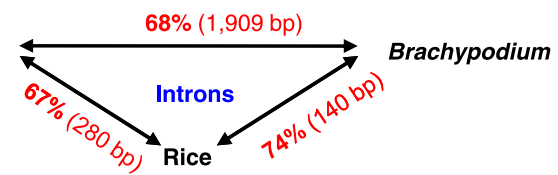

scoring segment pair (bp). e Combined intron identity (\%) and length of the high-scoring segment pair (bp)

both candidates Mot1 and FtsH4 were compared between NILs carrying either DV92 or G3116 alleles by semiquantitative (Fig. 4a) and real-time quantitative PCR (Fig. 4b). Transcripts of both genes Motl and FtsH4 were observed in apices, crowns, leaves, and spikes, but were not detected in roots (Fig. 4a). A comparison of the Mot1 and FtsH4 transcript levels in shoot apical regions by semiquantitative PCR showed no apparent differences between NILs carrying the either DV92 or G3116 Eps- $A^{m} 1$ alleles (Fig. 4a). Similar results were obtained at the initiation of the transition between the vegetative and reproductive stages
Fig. 4 a Semi-quantitative polymerase chain reaction (PCR) using primers designed from genes $(1,2) \operatorname{Mot} 1,(3,4)$ Fts H4, and $(5,6)$ elf $4 a$. cDNA samples obtained from $(1,3,5)$ different Triticum monococcum plant organs; and $(2,4,6)$ shoot apical meristem of $\mathrm{BC}_{5} \mathrm{~F}_{2}$ near isogenic line (NIL) 268-5 carrying the Eps- $A^{m} 1$ allele for early heading (G3116, bold), and NILs 268-3, 529-1, and 529-3 carrying the Eps- $A^{m} 1$ allele for late heading (DV92). The first four samples were extracted from apices at the double-ridge stage, and the last four at the terminal spikelet stage. b Real-time quantitative PCR of (1) Mot1 and (2) FtsH4, comparing transcript levels between NILs carrying the Eps- $A^{m} 1$ allele for early (G3116) and late (DV92) heading. Values in the $y$-axes are normalized and calibrated values using the formula $(1+\text { Efficency })^{-\Delta \Delta C_{\mathrm{T}}}$ Different calibrators were used for Mot1 and FtsH4, and therefore the Y scales for the two genes are not comparable. Error bars represent one standard error of the mean

A
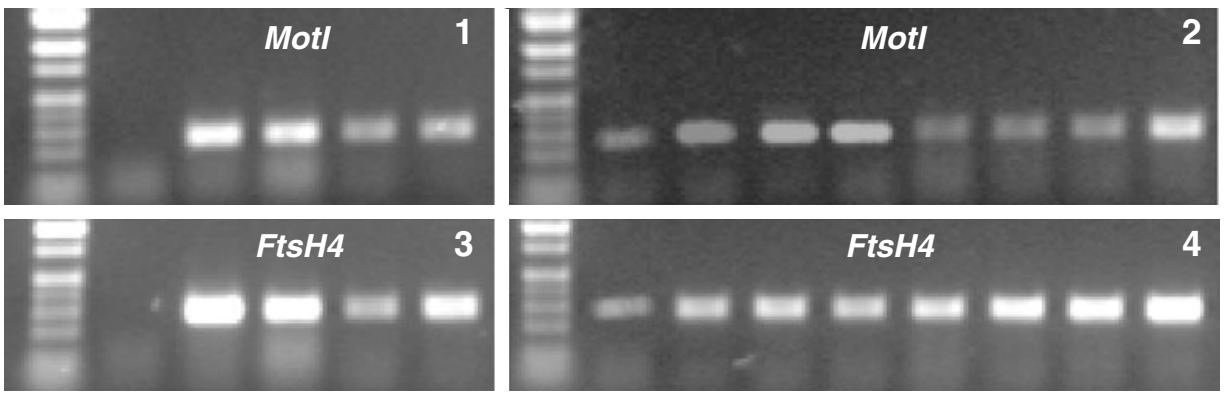

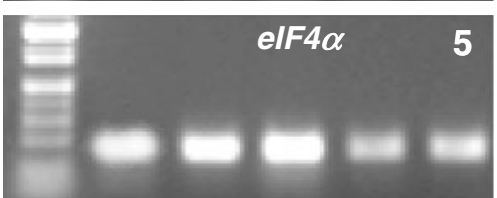

Root Crown Leaf Spike Apex

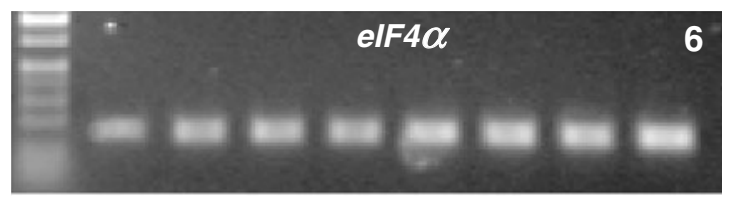

268-3 268-5 529-1 529-3 268-3 268-5 529-1 529-3

Double ridge

Terminal spikelet

B

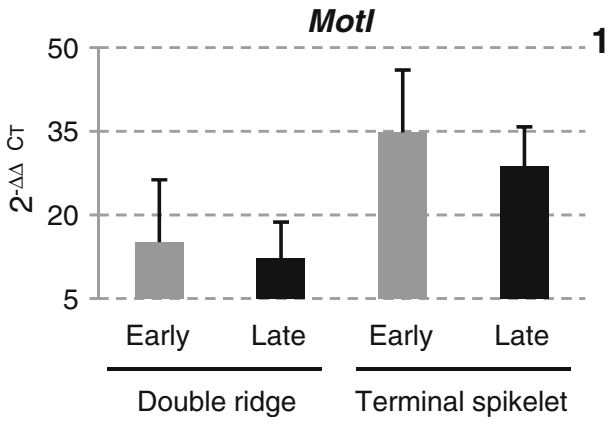

FtsH4

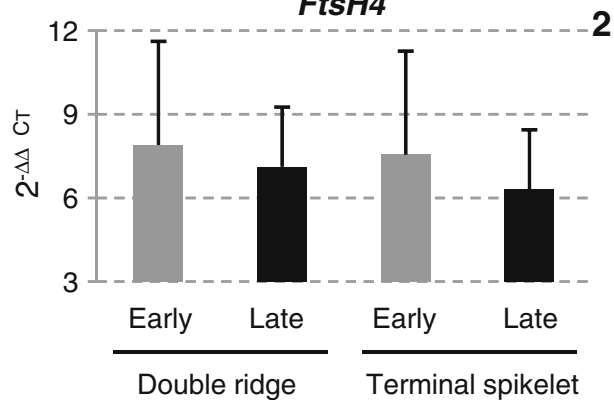


(double-ridge stage) and at the terminal spikelet stage (Fig. 4a). These results were confirmed by real-time quantitative PCR (Fig. 4b). The $2 \times 2$ ANOVAs showed non-significant interactions between genotypes (Eps- $A^{m} 1$ early and late alleles) and developmental stages (doubleridge and terminal spikelet; $P=0.86$ for Mot 1 and $P=0.94$ for Fts H4) and, therefore, the effects of the Eps- $A^{m} 1$ alleles were analyzed across developmental stages. Non-significant differences in the Mot1 and FtsH4 transcript levels $(P=0.64$ and $P=0.74$, respectively) were found between NILs carrying the DV92 or G3116 Eps- $A^{m} 1$ alleles.

\section{Discussion}

B. distachyon as a closer model species than rice for the large Triticeae genomes

Since the completion of the rice genomic sequence (Goff et al. 2002; Yu et al. 2002) several studies demonstrated a high level of colinearity between rice and the Triticeae genomes, which turned rice into the most commonly used model species for positional cloning projects in wheat (Bossolini et al. 2006, 2007; Dubcovsky et al. 2001; Faris et al. 2008; Yan et al. 2003, 2004, 2006). Even in those projects where the targeted gene was not present in the rice colinear region, the rice genome was still useful as a stepping stone to develop molecular markers in the wheat region (Fu et al. 2009; Uauy et al. 2006; Yan et al. 2004). However, the overall colinear gene framework between rice and the Triticeae genomes has been shown to be frequently interrupted by inversions, deletions, and insertions of genes, which sometimes complicates the use of rice as a model for the larger and more complex Triticeae genomes (Griffiths et al. 2006).

In 2001, Draper et al. questioned the value of rice as a model species for the temperate cereals and forage grasses given its relatively distant phylogenetic relation, its subtropical nature, and its specialized growth habit. He proposed B. distachyon as a better model than rice for both wheat and barley. Brachypodium is a temperate grass, and its small genome contains only approximately $15 \%$ of highly repetitive elements (Catalán et al. 1995).

In a phylogenetic tree of the Poaceae family based on combined data from chloroplast restriction sites and morphology, Kellogg (2001) showed that Brachypodium is more closely related to oat, Bromus, and wheat (subfamily Pooideae) than rice (subfamily Ehrhartoideae). This observation was also supported by sequence comparisons of ESTs (Vogel et al. 2006) and genes from both the leaf rust resistance locus Lr34 (Bossolini et al. 2007) and the domestication locus $Q$ (Faris et al. 2008) regions. Bossolini et al. (2007) estimated that the divergence of
Brachypodium from the Triticeae lineage occurred approximately 35 to 40 million years ago (Mya), significantly earlier than the divergence of these two groups of species from the rice lineage, which took place approximately 50 Mya (Paterson et al. 2004).

The present comparison of exon and intron sequences of the orthologous genes wg241, CA608558, and VatpC from the wheat, rice, and Brachypodium Eps 1 regions supported the previous conclusions. In all three cases, the predicted proteins were more similar between wheat and Brachypodium than between these two species and rice (Fig. 3). In addition, the comparison of the intron regions showed longer significantly similar segments between wheat and Brachypodium than between these two species and rice. This better conservation of the intron regions is important because it improves the ability of probes developed from Brachypodium genes to hybridize to wheat genomic DNAs or BAC clones.

In spite of the closer phylogenetic distance between Brachypodium and the Triticeae genomes relative to rice, the larger Triticeae genomes seem to have a higher proportion of colinearity exceptions when compared with the other two species. One inversion, one gene duplication, two gene insertions, and one gene insertion and duplication that were unique to the Triticeae species were found in this study (in addition to the non-colinear genes that might be present in the $0.75-\mathrm{cM}$ proximal gap of the T. monococcum physical map), whereas only one gene insertion ( $R b p l)$ was unique to $B$. distachyon, and none of the rice genes was simultaneously absent in both Triticeae species and Brachypodium. Similarly, the comparative study of the $Q$ locus region among wheat, rice, and Brachypodium showed multiple duplications of the T. monococcum gene $F B$ (from only one copy present in Brachypodium sylvaticum and none in rice to four copies present in T. monococcum), and a small inversion including one of the $F B$ copies (Faris et al. 2008). The comparison of the Lr34 locus orthologous regions among the same species revealed a large inversion in rice. However, excluding this main structural change, the gene content was more similar between rice and Brachypodium than between these two species and wheat. Thirtynine out of the 43 genes present in Brachypodium were present in rice $(91 \%)$, whereas only ten out of the 19 genes found in wheat $(53 \%)$ showed orthologues in either rice or Brachypodium. Interestingly, four of the wheat non-colinear genes showed evidence of movements associated with linked retroelements (Bossolini et al. 2007).

These last results suggest that the higher numbers of exceptions to gene colinearity observed in the Triticeae genomes might be associated with their larger genome size and their higher proportion of repetitive elements, many of which are actively transcribed (Echenique et al. 2002). Dubcovsky et al. (1996) pointed out that the RFLP maps of 
species with large genomes exhibited a higher proportion of duplicated loci (28\% in T. monococcum, $30 \%$ in barley, Kleinhofs et al. 1993) than the RFLP maps of species with smaller genomes, such as rice (6\%, Saito et al. 1991) or common bean ( $9 \%$, Nodari et al. 1993). Dubcovsky and Dvorak (2007) indicated that the high rate of turnover of repetitive elements in the intergenic regions of wheat was associated with faster changes in the gene regions. A recent study comparing a high-density SNP map of A. tauschii with the rice and sorghum genomes confirmed that $80 \%$ of the structural changes observed among these species occurred in the large genome of A. tauschii, whereas only $20 \%$ occurred in the smaller rice and sorghum genomes (Luo et al. 2009).

The higher rate of change associated with the large Triticeae genomes provides an explanation for the limitations of the Brachypodium genome as a better model than rice for the complex Triticeae genomes. Even though some changes are shared by Brachypodium and wheat relative to rice (e.g., the presence of genes CD892187, Mot1, and FtsH4 in this comparative study), most of the changes are unique to the Triticeae species. A corollary of this higher rate of structural changes in the large genomes (such us barley or A. tauschii) is that the sequencing of some of these large genomes is still necessary to better support positional cloning projects in the Triticeae species.

Eps- $A^{m} 1$ candidate genes

The use of both A. tauschii and B. distachyon as bridge species for the positional cloning of the Eps- $A^{m} 1$ gene in $T$. monococcum yielded two valuable results. First, the markers identified proximal to $A d k 1$ and completely linked to the Eps- $A^{m} 1$ locus were sufficient to reveal T. monococcum $\mathrm{BAC}$ clones covering this region and complete the distal side of the Eps- $A^{m} 1$ physical map. Second, and even more importantly, the mapping of genes Motl and FtsH4 completely linked to both the earliness per se and spikelet number phenotypes indicated that these two genes are valid candidates for Eps- $A^{m} 1$.

Mot1 The Mot1 gene has SNF2_N (pfam00176) and HELICc (cd00079) domains characteristic of the SNF2 family of transcriptional regulators. A phylogenetic analysis of these conserved domains from different protein members of this family in Arabidopsis, rice, and $S$. cerevisiae indicated that wheat and Brachypodium MOT1 proteins are more closely related to rice protein OsXP464189 and $S$. cerevisiae protein MOT1 than to other members of this family. This cluster was supported by $100 \%$ bootstrap values (Fig. S1a).
In yeast, MOT1 has been found to both activate and repress transcription by ATPase-dependent mechanisms (Dasgupta et al. 2002; Muldrow et al. 1999; Sprouse et al. 2006; Sudarsanam et al. 2000). Another member of the SNF2 family, the PHOTOPERIOD-INDEPENDENT EARLY FLOWERING gene 1 (PIE1; Fig. S1a), was shown to be required for the activation of both FLOWERING LOCUS C (FLC) and FRIGIDA (FRI) from the vernalization pathway, and also by the autonomous pathway that regulate flowering time in Arabidopsis (Noh and Amasino 2003). PIE1 was found to be expressed preferentially in the shoot apical meristem and to increase $F L C$ expression repressing the transition of the shoot apex from the vegetative to reproductive stages and delaying flowering time (Noh and Amasino 2003). Gene BRM, another Arabidopsis member of the same SNF2 family (Fig. S1a), was also shown to be expressed in meristems and to be required for normal vegetative and reproductive development (Farrona et al. 2004). BRM-silenced plants exhibited a smaller overall size with reduced stems and leaves, defects in floral organ size, number, and identity, and they flowered significantly earlier (Farrona et al. 2004). It was demonstrated that BRM controlled the transition of the shoot apical meristem from the vegetative to reproductive stages by affecting CONSTANS $(C O)$, a transcription factor from the photoperiod pathway that promotes flowering (Farrona et al. 2004).

The involvement of both genes PIEI and BRM in the regulation of flowering time and in the normal vegetative and reproductive development in Arabidopsis suggests that gene Mot1 is a potentially interesting candidate for Eps$A^{m} 1$. Gene Mot1 was found to be expressed both in the vegetative shoot apical meristem and in the developing spike in T. monococcum, which are the predicted tissues and developmental stages where Eps- $A^{m} 1$ is expected to act. However, non-significant differences were found by real-time quantitative PCR in the transcript levels of this gene between $\mathrm{BC}_{5} \mathrm{~F}_{2}$ NILs carrying either the Eps-A $A^{m} 1$ allele for late heading from DV92 or the Eps- $A^{m} 1$ allele for early heading from G3116 (Fig. 4).

Sequence comparison of the predicted MOT1 proteins from the DV92 and G3116 alleles revealed only two amino acid polymorphisms, both of them upstream the SNF2 N and HELICc conserved domains at non-conserved amino acid positions. Although the substitution of T in G3116 at position 362 (also conserved in A. tauschii) by I in DV92 has a negative BLOSUM62 score $(-2)$, indicative of different biochemical properties of the substituted amino acid, the occurrence of this change at a non-conserved position complicates the prediction of the effect of this amino acid change in the function of the protein. 
FtsH4 A phylogenetic analysis of the peptidase_M41 (pfam01434) and the AAA (cd00009) domains from several members of the FtsH family of proteases, including all the Arabidopsis and rice homologues, revealed that wheat and Brachypodium FtsH4 proteins are more closely related to Arabidopsis protein FtsH4 and rice proteins FtsH4 and FtsH5. This clade was supported by $100 \%$ bootstrap values (Fig. S1b). Yu et al. (2005) indicated that both rice genes FtsH4 and FtsH5 are arranged in tandem on rice chromosome 1, likely being the result of a duplication of a gene homologous to Arabidopsis gene FtsH4.

T. monococcum gene Fts $H 4$, the other Eps-A $A^{m} 1$-candidate gene, is an ATP-dependent metalloprotease from the M41 family of peptidases, which belongs to a larger family of proteins called AAA (ATPases associated with diverse cellular activities; van der Hoorn 2008). The Arabidopsis nuclear genome was found to contain $12 \mathrm{FtsH}$ genes, the products of three of which are targeted to mitochondria and the remaining nine to chloroplast (Sakamoto et al. 2003). In rice, at least nine $F t s H$ genes have been found, and each of them corresponds to an Arabidopsis $F$ ts $H$ gene or gene pair, except for gene Arabidopsis FtsH12. Rice genes FtsH4 and Fts $\mathrm{H} 5$ correspond to Arabidopsis Fts $\mathrm{H} 4$ and are targeted to the mitochondria (Yu et al. 2005; Fig. S1b).

Arabidopsis protein FtsH4 (Fig. S1b) has been shown to be part of the i-AAA protease complex that functions in the intermembrane mitochondrial space (Urantowka et al. 2005). Mutants for this gene revealed morphological, anatomical, and developmental alterations when grown under a short-day photoperiod. The Fts 44 gene was found to be highly expressed in seeds, and Arabidopsis ftsh 4 mutants showed a delayed germination. A developmental delay was maintained through all the developmental cycle and resulted in plants with reduced leaf number, later flowering time, and lower fertility (Gibala et al. 2009).

Based on the role of FtsH4 in Arabidopsis, this gene cannot be ruled out as a candidate for Eps- $A^{m} 1$. However, comparison of the predicted FtsH4 protein sequences from the DV92 and G3116 alleles revealed no amino acid substitution. In addition, semi-quantitative PCR analyses revealed that gene FtsH4 is present in both the vegetative apical meristem and the developing spike in T. monococcum, with no major differences between $\mathrm{BC}_{5} \mathrm{~F}_{2}$ NILs carrying the DV92 or G3116 Eps- $A^{m} 1$ alleles (Fig. 4a). These last results were also confirmed by real-time quantitative PCR (Fig. 4b).

Although currently it is not possible to rule out any of the two candidate genes, the negative BLOSUM62 score of one of the amino acid changes in the MOT1 protein and the known role of related SNF2-domain containing proteins on flowering time and development suggest that Mot1 might be a better candidate for Eps-A $A^{m} 1$ than FtsH4.

Future work and conclusions

To determine whether genes Mot1 or FtsH4 have the expected effects of Eps-A $A^{m} l$ on heading time, spike development, and spikelet number, mutants for the wheat orthologues of these two genes are being generated using an available tetraploid Targeting Induced Local Lesions IN Genomes population (TILLING; Uauy et al. 2009). Mutants for both the A and B genome copies of each gene will be then combined to produce double mutants and test their effects on heading time and spikelet number.

Currently, the existence of additional candidate genes completely linked to Eps- $A^{m} 1$ in the proximal $0.75 \mathrm{cM}$-gap of the T. monococcum physical map cannot be ruled out. An approximate calculation of the number of additional candidate genes that might be expected in this region can be obtained by assuming a direct proportionality between number of genes and genetic distances. Since 11 genes were found to be present within the $0.14-\mathrm{cM}$ region sequenced in $A$. tauschii, the additional $0.0125 \mathrm{cM}$ required to find a marker proximal to $E p s-A^{m} l$ (one recombination event from Mot1/FtsH4) is expected to yield only one more additional linked gene. If a constant ratio between genetic and physical distances is also assumed, this $0.0125 \mathrm{cM}$ region is expected to represent approximately $300 \mathrm{~kb}$, which can probably be covered in a limited number of additional chromosome walk steps in $T$. monococcum. However, ratios between recombination and gene number and between genetic and physical lengths are known to be variable along different chromosome regions, and therefore these predictions should be taken with caution.

The effect of the Eps- $A^{m} 1$ locus on heading time is known to be modulated by temperature (Bullrich et al. 2002). Therefore, the cloning of this gene has the potential to increase the understanding of complex interactions between temperature and plant development. In addition to this basic knowledge, the identification of the Eps-A $A^{m} 1$ gene has highly relevant practical implications, since this gene affects both the duration of spike development and the number of spikelets per spike, which is an important component of potential grain yield in wheat. It is interesting to point out that the A genome of polyploid wheat was contributed by $T$. urartu, a related but separate species from T. monococcum (Johnson and Dhaliwal 1976). Therefore, 10,000 years of independent domestication may have resulted in the origin of new and valuable alleles in the $\mathrm{A}^{\mathrm{m}}$ genome of T. monococcum that are not present in the A genome of $T$. urartu or polyploid wheat species. 
Acknowledgements This project was supported by the US Department of Agriculture, Cooperative State Research, Education, and Extension Services, grant number 2009-35304-05091.

Open Access This article is distributed under the terms of the Creative Commons Attribution Noncommercial License which permits any noncommercial use, distribution, and reproduction in any medium, provided the original author(s) and source are credited.

\section{References}

Abbott J, Aanensen D, Rutherford K, Butcher S, Spratt B (2005) Web ACT - an online companion for the Artemis Comparison Tool. Bioinform Appl Note 21(18):3665-3666

Akhunov ED, Akhunova AR, Dvorak J (2005) BAC libraries of Triticum urartu, Aegilops speltoides and Ae. tauschii, the diploid ancestors of polyploid wheat. Theor Appl Genet 111:1617-1622

Arumuganathan K, Earle ED (1991) Estimation of nuclear DNA content of plants by flow cytometry. Plant Mol Biol Rep 9:22123

Bennett MD, Bhandol P, Leitch IJ (2000) Nuclear DNA amounts in angiosperms and their modern uses: 807 new estimates. Ann Bot 86:859-909

Bennetzen JL, Ma J (2003) The genetic colinearity of rice and other cereals based on genomic sequence analysis. Curr Opin Plant Biol 6:128-133

Bennetzen JL, Ramakrishna W (2002) Exceptional haplotype variation in maize. Proc Natl Acad Sci USA 99(14):9093-9095

Bossolini E, Krattinger SG, Keller B (2006) Development of simple sequence repeat markers specific for the $L r 34$ resistance region of wheat using sequence information from rice and Aegilops tauschii. Theor Appl Genet 113:1040-1062

Bossolini E, Wicker T, Knobel PA, Keller B (2007) Comparison of orthologous loci from small grass genomes Brachypodium and rice: implications for wheat genomics and grass genome annotation. Plant J 49:704-717

Brunner S, Keller B, Feuillet C (2003) A large rearrangement involving genes and low copy DNA interrupts the microlinearity between rice and barley at the Rph7 locus. Genetics 164:673-683

Bullrich L, Appendino ML, Tranquilli G, Lewis S, Dubcovsky J (2002) Mapping of a thermo-sensitive earliness per se gene on Triticum monococcum chromosome $1 \mathrm{~A}^{\mathrm{m}}$. Theor Appl Genet 105:585-593

Catalán P, Shi Y, Amstrong L, Draper J, Stace CA (1995) Molecular phylogeny of the grass genus Brachypodium P. Beauv. based on RFLP and RAPD analysis. Bot J Linn Soc 117:263-280

Dasgupta A, Darst RP, Martin KJ, Afshari CA, Auble DT (2002) Mot1 activates and represses transcription by direct, ATPase-dependent mechanisms. Proc Natl Acad Sci USA 99(5):2666-2671

Devos KM (2005) Updating the 'crop circle'. Curr Opin Plant Biol $8: 155-162$

Devos KM, Gale MD (2000) Genome relationships: the grass model in current research. Plant Cell 12:637-646

Draper J, Mur LAJ, Jenkins G, Ghosh-Biswas GC, Bablak P, Hasterok R, Routledge APM (2001) Brachypodium distachyon. A new model system for functional genomics in grasses. Plant Physiol 127(4):1539-1555

Dubcovsky J, Dvorak J (2007) Genome plasticity a key factor in the success of polyploid wheat under domestication. Science 316 (5833):1862-1866

Dubcovsky J, Galvez AF, Dvorak J (1994) Comparison of the genetic organization of the early salt stress response gene system in salttolerant Lophopyrum elongatum and salt-sensitive wheat. Theor Appl Genet 87:957-964
Dubcovsky J, Luo MC, Zhong G-Y, Bransteiter R, Desai A, Kilian A, Kleinhofs A, Dvorak J (1996) Genetic map of diploid wheat, Triticum monococcum L., and its comparison with maps of Hordeum vulgare L. Genetics 143:983-999

Dubcovsky J, Ramakrishna W, SanMiguel PJ, Busso CS, Yan L, Shiloff BA, Bennetzen JL (2001) Comparative sequence analysis of collinear barley and rice bacterial artificial chromosomes. Plant Physiol 125:1342-1353

Dvorak J, Di Terlizzi P, Zhang HB, Resta P (1993) The evolution of polyploid wheats: identification of the A genome donor species. Genome 36:21-31

Dvorak J, Zhang HB (1990) Variation in repeated nucleotide sequences sheds light on the phylogeny of the wheat B and $G$ genomes. Proc Natl Acad Sci USA 87:9640-9644

Echenique V, Stamova B, Wolters P, Lazo G, Carollo V, Dubcovsky J (2002) Frequencies of Ty1-copia and Ty3-gypsy retroelements within the Triticeae EST databases. Theor Appl Genet 104:840-844

Ewing B, Green P (1998) Basecalling of automated sequencer traces using Phred II: error probabilities. Genome Res 8:186-194

Faris JD, Zhang Z, Fellers JP, Gill BS (2008) Micro-colinearity between rice, Brachypodium, and Triticum monococcum at the wheat domestication locus $Q$. Funct Integr Genomics 8:149-164

Farrona S, Hurtado L, Bowman JL, Reyes JC (2004) The Arabidopsis thaliana SNF2 homolog AtBRM controls shoot development and flowering. Development 131:4965-4975

Feuillet C, Keller B (2002) Comparative genomics in the grass family: molecular characterization of grass genome structure and evolution. Ann Bot 89:3-10

Feuillet C, Travella S, Stein N, Albar L, Nublat A, Keller B (2003) Map-based isolation of the leaf rust disease resistance gene $\mathrm{Lr} 10$ from the hexaploid wheat (Triticum aestivum L.) genome. Proc Natl Acad Sci USA 100:15253-15258

Fu D, Uauy C, Distelfeld A, Blechl A, Epstein L, Chen X, Sela H, Fahima T, Dubcovsky J (2009) A kinase-START gene confers temperature-dependent resistance to wheat stripe rust. Science 323(5919):1357-1360

Fu H, Zheng Z, Dooner HK (2002) Recombination rates between adjacent genic and retrotransposon regions in maize vary by two orders of magnitude. Proc Natl Acad Sci USA 99:1082-1087

Gibala M, Kicia M, Sakamoto W, Gola EM, Kubrakiewicz J, Smakowska E, Janska H (2009) The lack of mitochondrial AtFtsH4 protease alters Arabidopsis leaf morphology at the late stage of rosette development under short-day photoperiod. Plant J. doi:10.1111/j.1365-313X.2009.03907

Goff SA, Ricke D, Lan TH, Presting G, Wang R, Dunn M, Glazebrook J, Sessions A, Oeller P, Varma H, Hadley D, Hutchison D, Martin C, Katagiri F, Lange BM, Moughamer T, Xia Y, Budworth P, Zhong J, Miguel T, Paszkowski U, Zhang S, Colbert M, Sun WL, Chen L, Cooper B, Park S, Wood TC, Mao L, Quail P, Wing R, Dean R, Yu Y, Zharkikh A, Shen R, Sahasrabudhe S, Thomas A, Cannings R, Gutin A, Pruss D, Reid J, Tavtigian S, Mitchell J, Eldredge G, Scholl T, Miller RM, Bhatnagar S, Adey N, Rubano T, Tusneem N, Robinson R, Feldhaus J, Macalma T, Oliphant A, Briggs S (2002) A draft sequence of the rice genome (Oryza sativa L. ssp japonica). Science 296:92-100

Gordon D, Abajian C, Green P (1998) Consed: a graphical tool for sequence finishing. Genome Res 8:195-202

Griffiths S, Sharp R, Foote TN, Bertin I, Wanous M, Reader S, Colas I, Moore G (2006) Molecular characterization of $P h 1$ as a major chromosome pairing locus in polyploid wheat. Nature 439 (7077):749-752

Gu YQ, Coleman-Derr D, Kong X, Anderson OD (2004) Rapid genome evolution revealed by comparative sequence analysis of orthologous regions from four Triticeae genomes. Plant Physiol $135: 459-470$ 
Guyot R, Keller B (2004) Ancestral genome duplication in rice. Genome 47:610-614

Guyot R, Yahiaoui N, Feuillet C, Keller B (2004) In silico comparative analysis reveals a mosaic conservation of genes within a novel collinear region in wheat chromosome 1AS and rice chromosome $5 \mathrm{~S}$. Funct Integr Genomics 4:47-58

Huang S, Sirikhachornkit A, Su X, Faris J, Gill B, Haselkorn R, Gornicki P (2002) Genes encoding plastid acetyl-CoA carboxylase and 3-phosphoglycerate kinase of the Triticum/Aegilops complex and the evolutionary history of polyploid wheat. Proc Natl Acad Sci USA 99(12):8133-8138

Huo N, Gu YQ, Lazo GR, Vogel JP, Coleman-Derr D, Luo MC, Thilmony R, Garvin DF, Anderson OD (2006) Construction and characterization of two BAC libraries from Brachypodium distachyon, a new model for grass genomics. Genome 49(9):1099-1108

Johnson BL, Dhaliwal HS (1976) Reproductive isolation of Triticurn boeoticurn and Triticurn urartu and the origin of the tetraploid wheats. Am J Bot 63:1088-1094

Kellogg EA (2001) Evolutionary history of the grasses. Plant Physiol 125:1198-1205

Kleinhofs A, Kilian A, Saghai MA, Biyashev RM, Hayes P, Chen FQ, Lapitan N, Fenwick A, Blake TK, Kanazin V, Ananiev E, Dahleen L, Kudrna D, Bollinger J, Knapp SJ, Liu B, Sorrels M, Heun M, Franckowiak JD, Hoffman D, Skadsen R, Steffenson BJ (1993) A molecular, isozyme and morphological map of the barley (Hordeum vulgare) genome. Theor Appl Genet 86:705712

Kong CH, Hu F, Liang WJ, Wang P, Jiang Y (2004) Allelopathic potential of Ageratum conyzoides at various growth stages in different habitats. Allelopathy J 13:233-240

Lewis S, Faricelli ME, Appendino ML, Valárik M, Dubcovsky J (2008) The chromosome region including the earliness per se locus $E p s-A^{m} 1$ affects the duration of early developmental phases and spikelet number in diploid wheat. J Exp Bot 59(13):35953607

Lijavetzky D, Muzzi G, Wicker T, Keller B, Wing R, Dubcovsky J (1999) Construction and characterization of a bacterial artificial chromosome (BAC) library for the A genome of wheat. Genome 42:1176-1182

Linkiewicz AM, Qi LL, Gill BS, Echalier B, Chao S, Lazo GR, Hummel DD, Anderson OD, Akhunov ED, Dvorak J, Pathan MS, Nguyen HT, Peng JH, Lapitan NLV, Miftahudin GJP, La Rota CM, Sorrells ME, Hossain KG, Kalavacharla V, Kianian SF, Sandhu D, Bondareva SN, Gill KS, Conley EJ, Anderson JA, Fenton RD, Close TJ, McGuire PE, Qualset CO, Dubcovsky J (2004) A 2500-locus bin map of wheat homoeologous group 5 provides insights on gene distribution and colinearity with rice. Genetics 168:665-676

Liu B, Segal G, Rong JK, Feldman M (2003) A chromosome-specific sequence common to the B genome of polyploid wheat and Aegilops searsii. Plant Syst Evol 241:55-66

Livak KJ, Schmittgen TD (2001) Analysis of relative gene expression data using real-time quantitative PCR and the $2^{-\Delta \Delta \mathrm{C}_{\mathrm{T}}}$ method. Methods 4:402-408

Luo MC, Deal KR, Akhunov ED, Akhunova AR, Anderson OD, Anderson JA, Blake N, Clegg MT, Coleman-Derr D, Conley EE, Crossman CC, Dubcovsky J, Gill BS, Gu YQ, Hadam J, Heo H, Huo N, Lazo G, Lundy KE, Ma Y, Matthews DE, McGuire PE, Morrell PL, Nicolet CM, Qualset CO, Renfro J, Tabanao D, Talbert LE, Tian C, Toleno DM, Warburton ML, You FM, Zhang W, Dvorak J (2009) Grass genome comparisons reveal the dominant mechanism of chromosome number reduction and accelerated genome evolution in the large Triticeae genomes. Proc Natl Acad Sci USA 106(37):15780-15785

Moore G (1995) Cereal genome evolution: pastoral pursuits with 'Lego' genomes. Curr Opin Genet Dev 5:717-724
Muldrow TA, Campbell AM, Weil PA, Auble DT (1999) MOT1 can activate basal transcription in vitro by regulating the distribution of TATA binding protein between promoter and nonpromoter sites. Mol Cell Biol 19:2835-2845

Nodari RO, Tsai SM, Gilbertson RL, Gepts P (1993) Towards an integrated linkage map of common bean. II. Development of an RFLP-based linkage map. Theor Appl Genet 85:513-520

Noh YS, Amasino RM (2003) PIE1, an ISWI family gene, is required for FLC activation and floral repression in Arabidopsis. Plant Cell 15(7):1671-1682

Paterson AH, Bowers JE, Burow MD, Draye X, Elsik CG, Jiang CX, Katsar CS, Lan TH, Lin YR, Ming R, Wright RJ (2000) Comparative genomics of plant chromosomes. Plant Cell 12:1523-1539

Paterson AH, Bowers JE, Chapman BA (2004) Ancient polyploidization predating divergence of the cereals, and its consequences for comparative genomics. Proc Natl Acad Sci USA 101:9903-9908

Peng JH, Zadeh H, Lazo GR, Gustafson JP, Chao S, Anderson OD, Qi LL, Echalier B, Gill BS, Dilbirligi M, Sandhu D, Gill KS, Greene RA, Sorrells ME, Akhunov ED, Dvorak J, Linkiewicz AM, Dubcovsky J, Hossain KG, Kalavacharla V, Kianian SF, Mahmoud AA, Miftahudin CEJ, Anderson JA, Pathan MS, Nguyen HT, McGuire PE, Qualset CO, Lapitan NLV (2004) Chromosome bin map of expressed sequence tags in homoeologous group 1 of hexaploid wheat and homoeology with rice and Arabidopsis. Genetics 168:609-623

Saito A, Yano M, Kishimoto N, Nakagahra M, Yoshimura A, Saito K, Kuhara S, Ukai Y, Kawase M, Nagamine T, Yoshimura S, Ideta O, Ohsawa R, Hayano Y, Iwata N, Sugiura M (1991) Linkage map of restriction fragment length polymorphism loci in rice. Jpn J Breed 41:655-670

Sakamoto W, Zaltsman A, Adam Z, Takahashi Y (2003) Coordinated regulation and complex formation of YELLOW VARIEGATED1 and YELLOW VARIEGATED2, Chloroplastic FtsH metalloproteases involved in the repair cycle of photosystem II in Arabidopsis thylakoid membranes. Plant Cell 15:2843-2855

SanMiguel P, Ramakrishna W, Bennetzen JL, Busso CS, Dubcovsky J (2002) Transposable elements, genes and recombination in a 215$\mathrm{kb}$ contig from wheat chromosome 5A. Funct Integr Genomics 2:70-80

Song R, Messing J (2003) Gene expression of a gene family in maize based on non-collinear haplotypes. Proc Natl Acad Sci USA 100:9055-9060

Sorrells ME, La Rota M, Bermudez-Kandianis CE, Greene RA, Kantety R, Munkvold JD, Miftahudin MA, Ma X, Gustafson PJ, Qi LL, Echalier B, Gill BS, Matthews DE, Lazo GR, Chao S, Anderson OD, Edwards H, Linkiewicz AM, Dubcovsky J, Akhunov ED, Dvorak J, Zhang D, Nguyen HT, Peng J, Lapitan NLV, Gonzalez-Hernandez JL, Anderson JA, Hossain K, Kalavacharla V, Kianian SF, Choi DW, Close TJ, Dilbirligi M, Gill KS, Steber C, Walker-Simmons MK, McGuire PE, Qualset CO (2003) Comparative DNA sequence analysis of wheat and rice genomes. Genome Res 13:1818-1827

Sprouse RO, Brenowitz M, Aubele DT (2006) Snf2/Swi2-related ATPase Mot1 drives displacement of TATA-binding protein by gripping DNA. EMBO J 25:1492-1504

Stein N, Feuillet C, Wicker T, Schlagenhauf E, Keller B (2000) Subgenome chromosome walking in wheat: A $450-\mathrm{kb}$ physical contig in Triticum monococcum L. spans the Lr10 resistance locus in hexaploid wheat (Triticum aestivum L.). Proc Natl Acad Sci USA 97(24):13436-13441

Sudarsanam P, Iyer VR, Brown PO, Winston F (2000) Whole-genome expression analysis of snf/swi mutants of Saccharomyces cerevisiae. Proc Natl Acad Sci USA 97:3364-3369

Uauy C, Distelfeld A, Fahima T, Blechl A, Dubcovsky J (2006) A NAC gene regulating senescence improves grain protein, zinc, and iron content in wheat. Science 314:1298-1301 
Uauy C, Paraiso F, Colasuonno P, Tran RK, Tsai H, Berardi S, Comai L, Dubcovsky J (2009) A modified TILLING approach to detect induced mutations in tetraploid and hexaploid wheat. BMC Plant Biology 9:115-129

Urantowka A, Knorpp C, Olczak T, Kolodziejczak M, Janska H (2005) Plant mitochondria contain at least two $i$-AAA-like complexes. Plant Mol Biol 59:239-252

Valárik M, Linkiewicz AM, Dubcovsky J (2006) A microcolinearity study at the earliness per se gene Eps- $\mathrm{A}^{\mathrm{m}} 1$ region reveals an ancient duplication that preceded the wheat-rice divergence. Theor Appl Genet 112:945-957

Van der Hoorn RAL (2008) Plant proteases: from phenotypes to molecular mechanisms. Annu Rev Plant Biol 59:191-223

Van Deynze AE, Dubcovsky J, Gill KS, Nelson JC, Sorrells ME, Dvorak J, Gill BS, Lagudah ES, McCouch SR, Appels R (1995) Moleculargenetic maps for group I chromosomes of Triticeae species and their relation to chromosomes in rice and oat. Genome 38:45-59

Vogel JP, Gu YQ, Twigg P, Lazo GR, Laudencia-Chingcuanco D, Hayden DM, Donze TJ, Vivian LA, Stamova B, Coleman-Derr D (2006) EST sequencing and phylogenetic analysis of the model grass Brachypodium distachyon. Theor Appl Genet 113:186-195

Wicker T, Yahiaoui N, Guyot R, Schlagenhauf E, Liu ZD, Dubcovsky J, Keller B (2003) Rapid genome divergence at orthologous low molecular weight glutenin loci of the $\mathrm{A}$ and $\mathrm{A}^{\mathrm{m}}$ genomes of wheat. Plant Cell 15:1186-1197

Yahiaoui N, Srichumpa P, Dudler R, Keller B (2004) Genome analysis at different ploidy levels allows cloning of the powdery mildew resistance gene $P m 3 b$ from hexaploid wheat. Plant J 37:528-538
Yan L, Fu D, Li C, Blechl A, Tranquilli G, Bonafede M, Sanchez A, Valárik M, Yasuda S, Dubcovsky J (2006) From the cover: the wheat and barley vernalization gene VRN3 is an orthologue of FT. Proc Natl Acad Sci USA 103:19581-19586

Yan L, Loukoianov A, Blechl A, Tranquilli G, Ramakrishna W, SanMiguel P, Bennetzen JL, Echenique V, Dubcovsky J (2004) The wheat $V R N 2$ gene is a flowering repressor down-regulated by vernalization. Science 303:1640-1644

Yan L, Loukoianov A, Tranquilli G, Helguera M, Fahima T, Dubcovsky J (2003) Positional cloning of the wheat vernalization gene VRN1. Proc Natl Acad Sci USA 100(10):6263-6268

Yu F, Park S, Rodermel S (2005) Functional redundancy of AtFtsH metalloproteases in thylakoid membrane complexes. Plant Physiol 138:1957-1966

Yu J, Hu S, Wang J, Wong GK, Li S, Liu B, Deng Y, Dai L, Zhou Y, Zhang X, Cao M, Liu J, Sun J, Tang J, Chen Y, Huang X, Lin W, Ye C, Tong W, Cong L, Geng J, Han Y, Li L, Li W, Hu G, Huang X, Li W, Li J, Liu Z, Li L, Liu J, Qi Q, Liu J, Li L, Li T, Wang X, Lu H, Wu T, Zhu M, Ni P, Han H, Dong W, Ren X, Feng X, Cui $\mathrm{P}$, Li X, Wang H, Xu X, Zhai W, Xu Z, Zhang J, He S, Zhang J, Xu J, Zhang K, Zheng X, Dong J, Zeng W, Tao L, Ye J, Tan J, Ren X, Chen X, He J, Liu D, Tian W, Tian C, Xia H, Bao Q, Li G, Gao H, Cao T, Wang J, Zhao W, Li P, Chen W, Wang X, Zhang Y, Hu J, Wang J, Liu S, Yang J, Zhang G, Xiong Y, Li Z, Mao L, Zhou C, Zhu Z, Chen R, Hao B, Zheng W, Chen S, Guo W, Li G, Liu S, Tao M, Wang J, Zhu L, Yuan L, Yang H (2002) A draft sequence of the rice genome (Oryza sativa L. ssp. indica). Science 296:79-92 